\title{
Chapter 6 \\ The Governance Context of Drought Policy and Pilot Measures for the Arzal Dam and Reservoir, Vilaine Catchment, Brittany, France
}

\author{
Isabelle La Jeunesse, Corinne Larrue, Carina Furusho, \\ Maria-Helena Ramos, Alison Browne, Cheryl de Boer, \\ Rodrigo Vidaurre, Louise Crochemore, Jean-Pierre Arrondeau \\ and Aldo Penasso
}

\subsection{Introduction}

This chapter presents an analysis of the drought adaptation governance of the Vilaine catchment in the Brittany region in France and, more specifically, of the Arzal dam and reservoir located at the outlet of the river. Accordingly, the analysis focuses on the lower part of the Vilaine catchment, where two pilot studies were conducted during the DROP project. The material for the analysis was collected during two field visits. The first visit occurred from 16 to 18 September 2013, and the second from 16 to 18 June 2014, during which the Governance Team (GT) met stakeholders, managers and representatives of the relevant local action groups. The analysis is also based on several documents provided by the Institution d'Aménagement de la Vilaine (IAV),

I. La Jeunesse $(\square) \cdot C$. Larrue

University of Tours, 33, allée Ferdinand de Lesseps, 37204 Tours, CX 3, France

e-mail: isabelle.lajeunesse@univ-tours.fr

C. Furusho · M.-H. Ramos · L. Crochemore

ISTEA, Rue Pierre-Gilles de Gennes 1, Antony, France

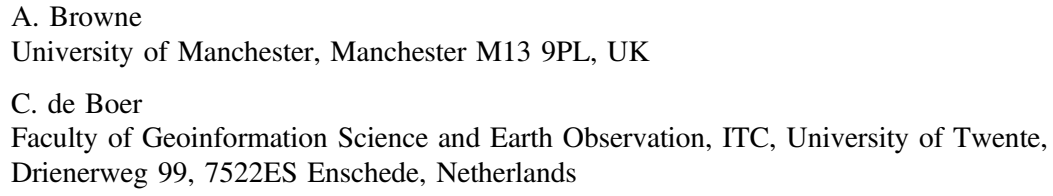

R. Vidaurre

Ecologic Institute, Pfalzburger Strasse 43/44, 10717 Berlin, Germany

J.-P. Arrondeau · A. Penasso

Institution d'Aménagement de la Vilaine, Pfalzburger Strasse 43/44, La Roche Bernard,

France

H. Bressers et al. (eds.), Governance for Drought Resilience,

DOI 10.1007/978-3-319-29671-5_6 
one practice partner of the DROP project responsible for the management of the Arzal dam and its reservoir. IAV also plays a key role in supporting water management at the catchment scale of the Vilaine River.

After a presentation of the French drought context (Sect. 6.2), including the description of the water management and drought adaptation strategies adopted in France, this chapter describes the main water use management issues for the Arzal dam and reservoir (Sect. 6.3). Section 6.4 is dedicated to the interpretation of the results of the drought governance analysis which was supported by the implementation of the drought governance assessment tool (GAT). Finally, in Sect. 6.5, some recommendations are proposed regarding possible measures to improve local drought adaptation strategies.

\subsection{National Drought Governance Context}

\subsubsection{Some Past Drought Events and Consequences on Water Policy}

Periods of drought experienced in France since the 1970s (Corti et al. 2009) have usually led to changes in national policies or in drought adaptation measures. The main characteristics and impacts of four major events are presented in Table 6.1.

The drought of 1976 was especially severe in the northern half of the country, also affecting other parts of northwestern Europe (Le Roy Ladurie et al. 2011). Given the strong impacts of this drought on the agricultural sector, the French government provided assistance to farmers with funds collected from the creation of a new "drought tax". The drought of 1989 also saw a large deficit in soil moisture. Although a drinking water supply could be ensured in most cases, measures concerning prohibitions or restrictions on certain water uses had to be adopted. The situation highlighted the general lack of regulation in France: the inability to quantify water abstraction, the absence of groundwater abstraction control and the lack of regulatory tools for allowing the authorities to allocate the remaining resources. In this context, the revision of the 1964 Water Law in France was accelerated, with a new revision being passed in 1992. Under the provisions of the current Environmental Code, the Prefects (the State representatives in the French decentralization process initiated in the 1980s) can take exceptional measures to address a possible lack of water resources. The drought of 2003 and its exceptional heat wave led to the creation of a Drought Action Plan (Plan d'Action Sécheresse), aiming to reconcile different water uses while preserving the quality of aquatic environments. In addition, a National Drought Committee (Comité Sécheresse) was created to coordinate water uses during drought crises. This Committee meets when needed depending on the hydrological situation immediately before or during a dry period. The Low Flow Management Plan (Plan de gestion des étiages, PGE) and the Drought Action Plan were implemented as operational tools for the management of hydrological droughts. The drought of 2011 
6 The Governance Context of Drought Policy and Pilot Measures ...

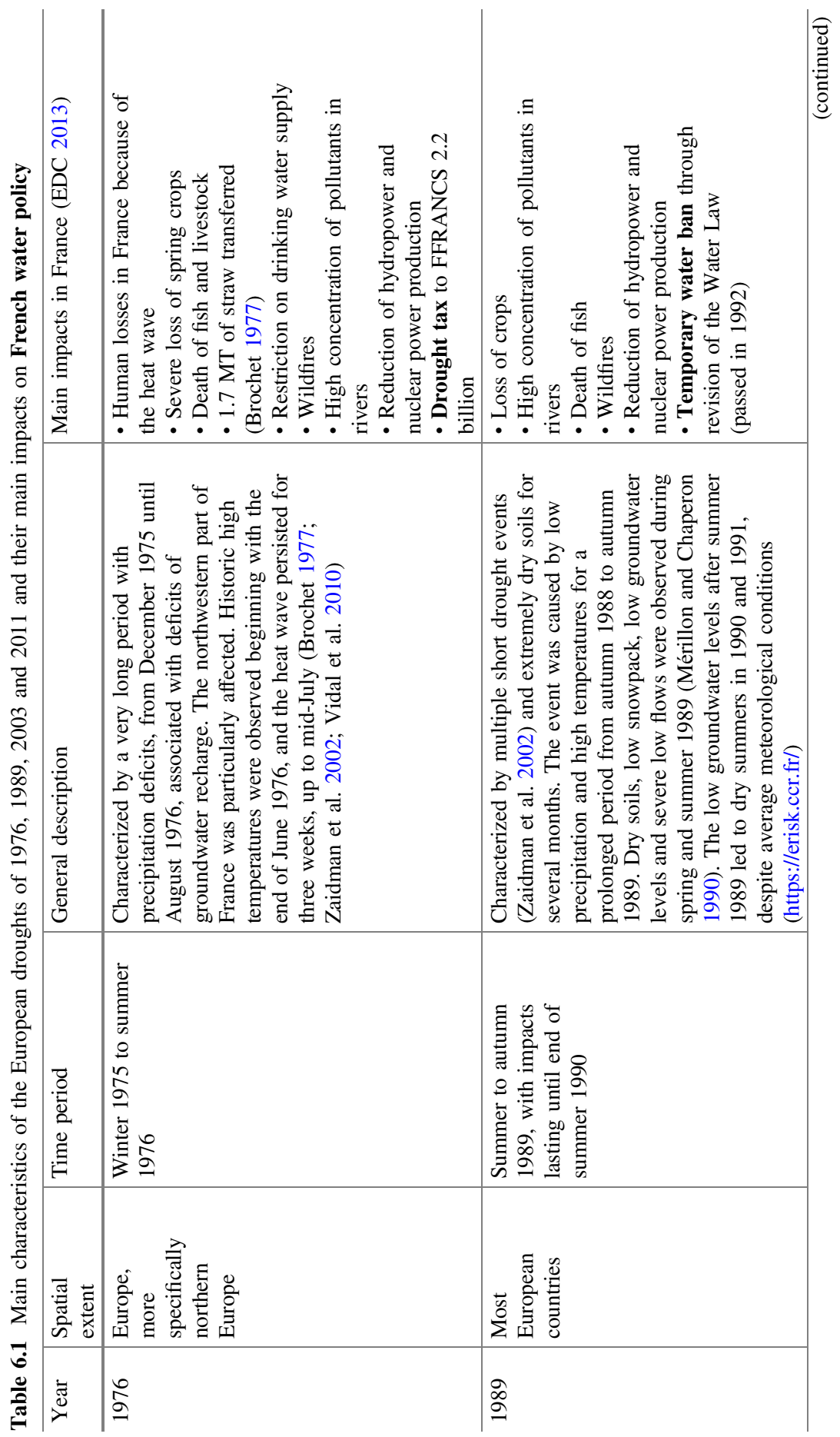




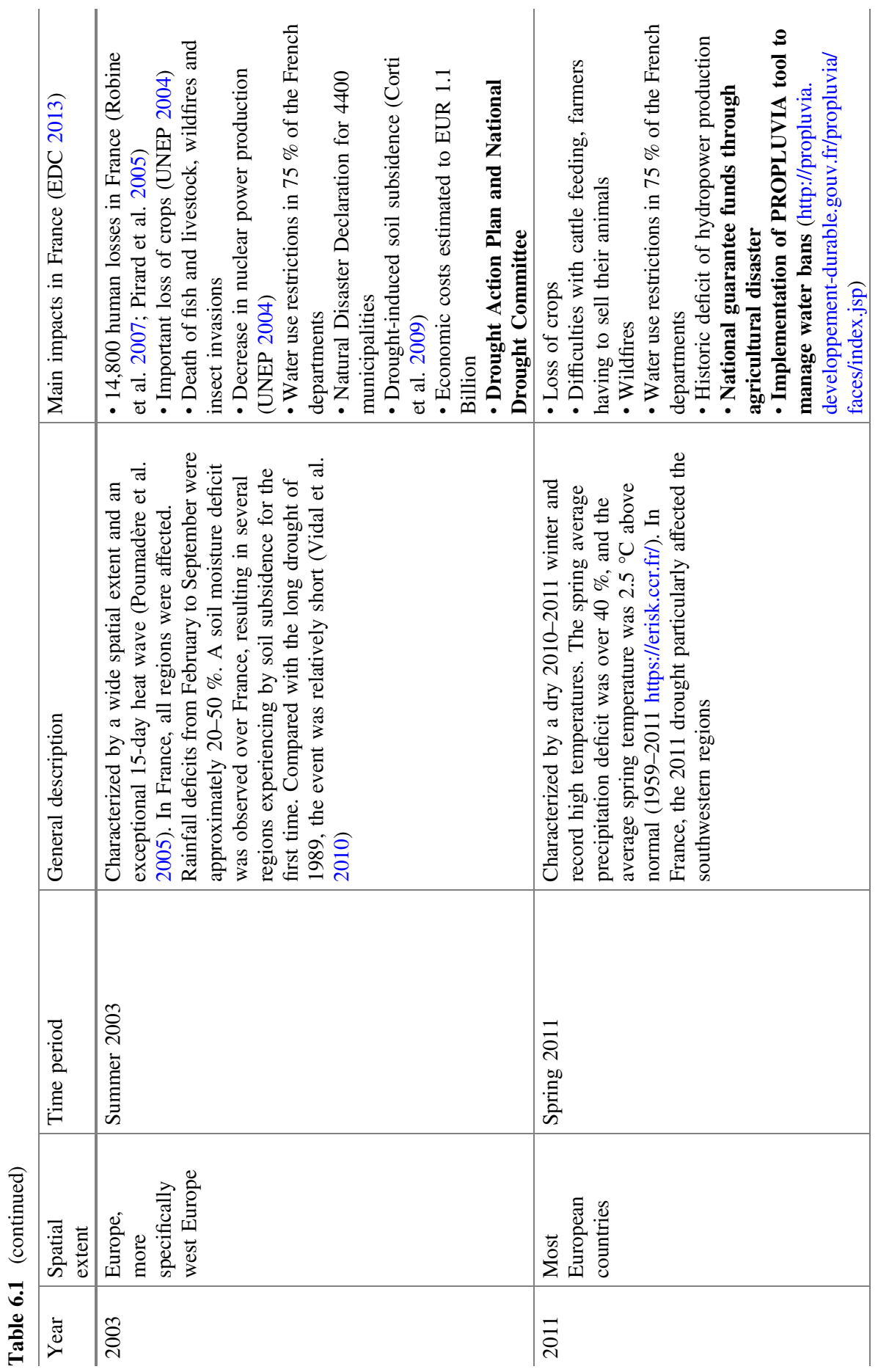


strongly impacted the agricultural, animal farming and energy sectors. Its impact on agriculture was comparable, in its severity, to the 1976 drought (Vidal et al. 2008, 2010). To cope with this drought, the French Ministry of Agriculture provided several hundred million euros in financial assistance to farmers under the national guarantee fund, specifically dedicated to agricultural disasters.

\subsubsection{Water Management in France}

France is divided into administrative regions and departments. For water, the territory is divided into twelve hydrographic districts each having its own river basin committee (Comité de Bassin) composed of representatives of the local authorities $(40 \%)$, water users $(40 \%)$ and State representatives $(20 \%)$. The committee establishes guidelines according to the European Water Framework Directive (WFD) and national water policies (Water Law since 1992, updated in 2006 under the LEMA law name). The guidelines are driven by the river basin management plan (SDAGE, Schéma Directeur d'Aménagement et de Gestion des Eaux), the six-year catchment-wide development and environmental plan promoted by water agencies (Agences de l'eau) (Fig. 6.1).

At the national level, the central government is in charge of all regulation issues (e.g. authorizations for water abstractions and pollution, monitoring and control of implementation by water users). The Water Management Direction and the French Ministry of Ecology, Sustainable Development and Energy are responsible for defining water management policies, including drought control and drought management plans for areas sensitive to droughts.

Within the territory, the decision and implementation of water regulation and drought control policies relies strictly on the Prefects of the departments, who have represented the central government at this level since 1982. Prefects are empowered to issue, implement, coordinate and control general and individual bylaws (Arrêtés) on water use, and, particularly, on drought control, through water bans, determined with the local support of mayors of municipalities and regional ministry entities (DREAL).

As concrete operational management is conducted at a river basin scale, local initiatives have an increasing role in water management in France. While the water agencies manage very large river basins, local issues are managed by groups of local authorities around a river section - the public body called EPTB (Etablissement Public Territorial de Bassin), which is similar to the 'waterboards' in the Netherlands. An EPTB, status established in 1997, can act in three areas: hydraulics (low-flow management, flood prevention, water production), environment (actions for migratory fish, maintenance of the banks, basin observatories) and local development (actions towards natural and cultural heritage). EPTBs have the status of interdepartmental institutions or joint local authorities. Their funding is provided by their own members. EPTBs are usually the coordinators of the SAGE (Schéma d'Aménagement et de Gestion de l'Eau), which is the water management plan at the sub-catchment level. SAGE is a non-constrained structure that acts 


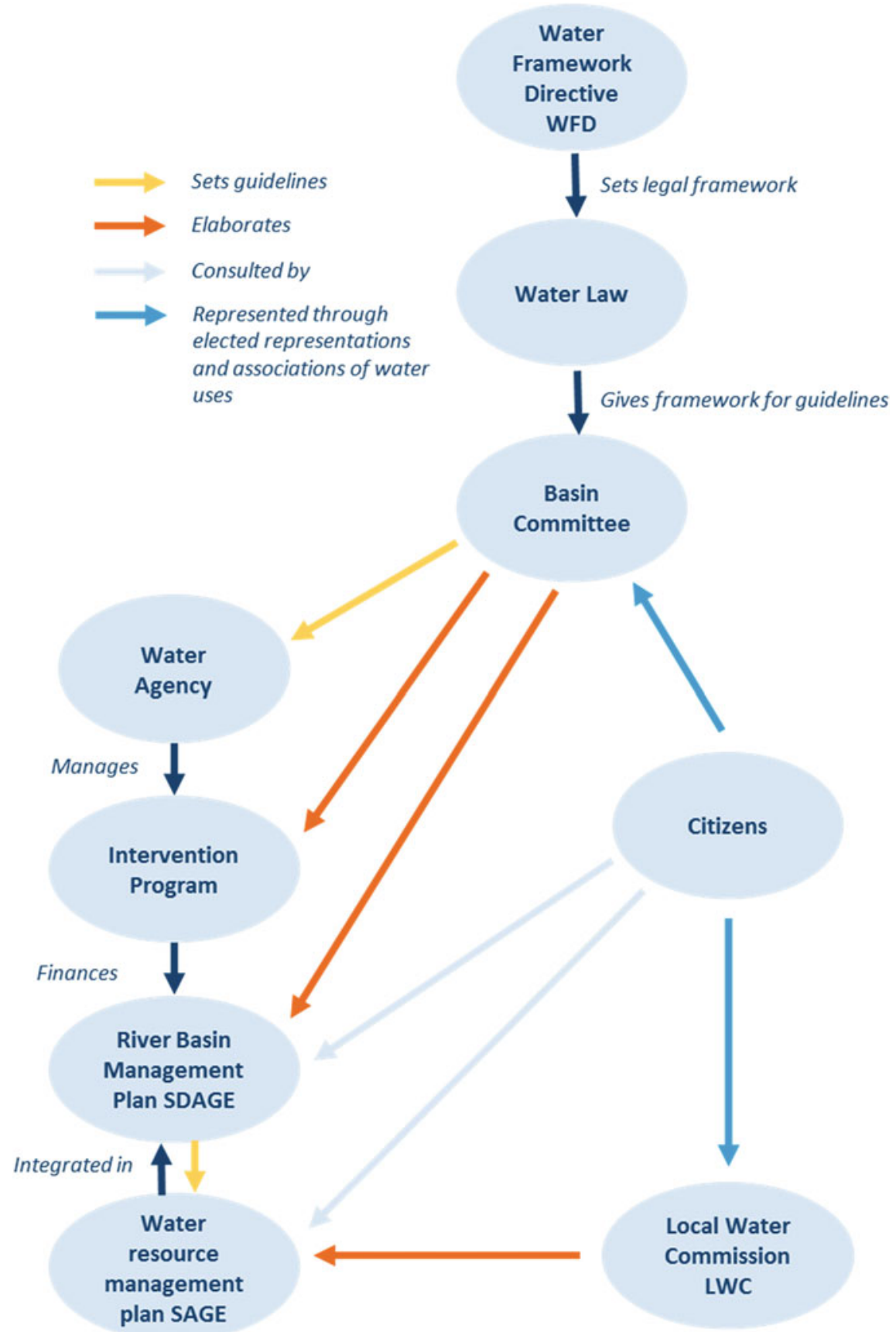

Fig. 6.1 Water management in France 
through a Local Water Commission (LWC, or CLE for Commission Locale de l'Eau in French) composed of State representatives (25\%), local authorities (50\%) and users $(25 \%)$. The members of the LWC are, thus, the main actors in the development of the SAGE.

Since 2006, the SAGE includes a plan for sustainable management of water resources and aquatic environments within a new document, the PAGD (Plan d'Aménagement et de Gestion Durable de la ressource en eau et des milieux aquatiques), with a plan of action aiming at achieving good ecological status for the sub-river basin. Urban planning documents must also comply with the objectives of water resource protection defined by the SAGE.

\subsubsection{Drought Adaptation in France}

In response to the frequency of water scarcity situations that occurred during the drought episodes observed at the end of the twentieth century, as described in Sect. 6.2.1, the French public authorities have gradually developed drought control policies and short-term mitigation action plans. Drought control management in France is now part of the legal frameworks and procedures governing general national water management. Measures to address droughts have two primary basic aspects: crisis management through emergency actions and mean to long-term quantitative/qualitative water resources management. The former involves measures set up within the framework of the river basin management plans (SDAGE), while the latter is more related to the national plan that copes with climate issues, which is implemented through the regional climate change action plans (named SRCAE, for Schéma regional climat, air, énergie, and meaning "Regional Scheme for Climate, Air and Energy").

\subsubsection{Emergency Actions}

Temporary periods of drought and water scarcity in France are generally managed through emergency actions, such as water use bans on non-priority uses, which are under the authority of the State. Bylaws imposing individual and collective restrictions and bans on water use are temporary. Drought control measures must be proportional to the water scarcity level and adapted to the required mitigation actions. In 2005, methodological guidelines to be followed in the case of a drought were published by the national government. This document recommends a progressive phasing of four levels of alert (monitoring/alert/crisis/critical crisis), which are adapted to the local water resource situation and historical background. It can be supported by the online cartographic tool PROPLUVIA. ${ }^{1}$

\footnotetext{
${ }^{1}$ http://propluvia.developpement-durable.gouv.fr/propluvia/faces/index.jsp.
} 
With the Drought Action Plan that was officially implemented in 2004, each region is to maintain updated information on the regional context (geographical features, climatology, hydrological aspects, etc.), the actors involved in decision-making, the areas sensitive to droughts, the different river discharge values that define critical low-flow thresholds to support the characterization of four levels of alert, the mayor's role in the process, the past water abstraction restrictions and the methods of communication and public information, all this in collaboration with the SDAGE river basin management plan. The objective is to improve the water resource monitoring systems and the coherence of bans on water uses, as well as to enhance the coordination of actions at the catchment scale, especially between upstream and downstream water users from different administrative units.

Since January 2012, a national observatory whose purpose is to study low flows (Observatoire National Des Etiages, ONDE) has been implemented by the National Agency for Water and Aquatic Environments ${ }^{2}$ (ONEMA). This observatory has a dual purpose: building a solid database of knowledge on summer low flows and developing tools to manage drought crises. In France, the south and southwestern regions are currently the most sensitive regions to droughts, while the north and northwestern regions generally do not require long-lasting water bans. However, even in a catchment located in northwestern France, as is the case for the Vilaine catchment, although it rarely suffers from severe droughts compared to what is observed in the southern part of the country, it can happen that water managers have to face episodic problems of imbalance between water availability and demand. This can create situations where it becomes difficult to satisfy all uses and where tensions may occur.

\subsubsection{National Plan to Cope with Climate Change}

Within the recent national climate adaptation action plan driven by the Ministry for the Environment (Plan national d'adaptation de la France aux effets du changement climatique 2011-2015), a set of actions regarding drought and water scarcity is proposed. The following hierarchical priorities are considered regarding the types of measures to be taken or planned:

- No-regret measures, which are beneficial even without climate change: in the field of water, for instance, it includes the promotion of water saving;

- Reversible measures, which give leeway of action for adaptation: in the field of water, measures such as the revision of levels of reference for flood prevention or low-flow control;

- Long-term measures, such as the integration of climate change in the long-term plans for drought adaptation;

- Measures that can be revised periodically as improved knowledge becomes available.

\footnotetext{
${ }^{2}$ A national public agency whose mission is to restore the healthy ecological status of water and aquatic environments, within the goal set by the European Water Framework Directive.
} 
Regional responsibility for climate change adaptation lies within the Regional Scheme for Climate, Air and Energy (SRCAE) and the Climate-Energy Plans (PCET), which are currently being developed at the local level (i.e. for municipalities with 50,000 inhabitants or more).

\subsection{Geo-Hydro Context, Drought Policy Focus and Measures Taken in the Vilaine}

\subsubsection{The Vilaine River}

\subsubsection{Hydrological Description}

The Vilaine River is a river nearly $230 \mathrm{~km}$ long flowing into the Atlantic Ocean. Its catchment area, located in the Loire-Bretagne river basin (Fig. 6.2), is 10,400 $\mathrm{km}^{2}$ in size. In 2012, the catchment area of the Vilaine had 1,260,000 inhabitants. In approximately 1960, actions were undertaken to restore navigability on the lower Vilaine River and boost the economic development of its main city, Redon. The aim was to stimulate local industry while reducing flooding and desalinating the marsh so it could be devoted to agricultural activities.

The catchment receives an annual average of 700-800 mm/year of precipitation. Mean daily flows are higher from December to March, with an average of $150 \mathrm{~m}^{3} / \mathrm{s}$,

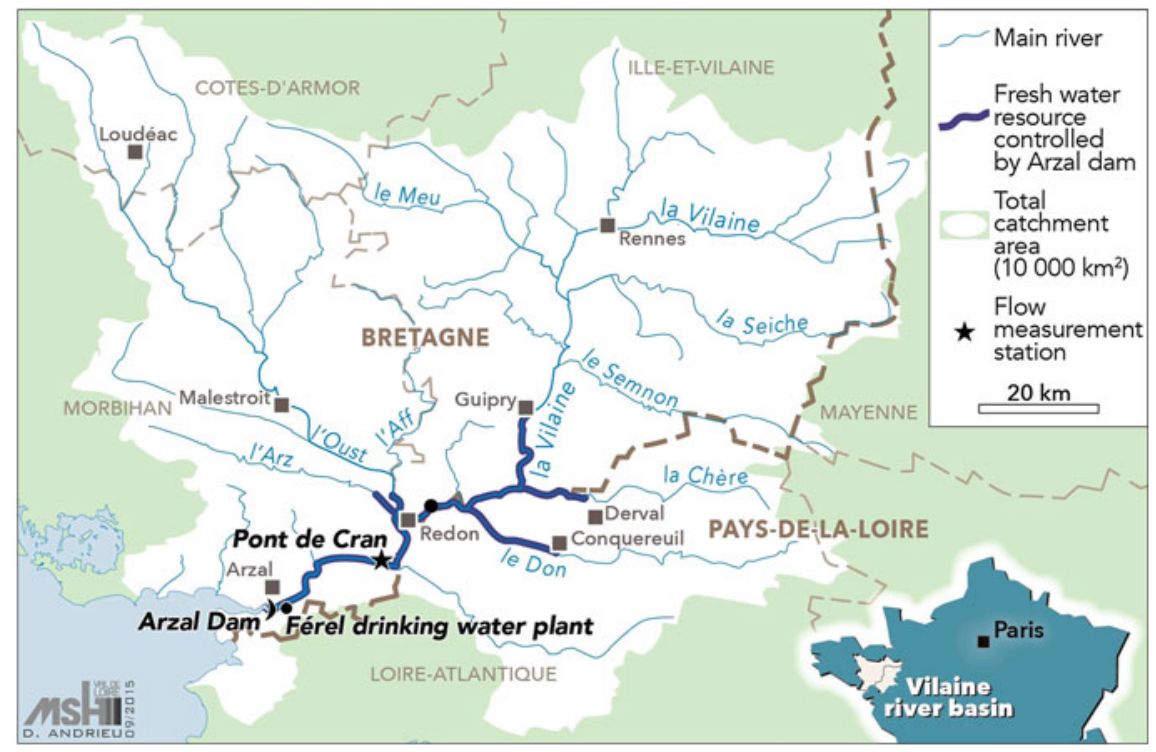

Fig. 6.2 Location of the Vilaine catchment, the Arzal dam and the zone of influence of the dam in the upper part of the riverbed 
while they are significantly lower from July to October, with an average of $15 \mathrm{~m}^{3} / \mathrm{s}$. In the Vilaine catchment, the low-flow period runs from May/June to October.

\subsubsection{Drought Threats and Water Scarcity in the Vilaine Catchment}

Traditionally considered to enjoy water in abundance, the northwestern regions of France do not always have drought policy and management plans formulated at the river basin scale. In the Vilaine River, however, provisions have been taken to create frameworks for some main water-related issues, notably for drinking water distribution and low-flow management in some sensitive parts of the catchment. In fact, the Vilaine catchment is heterogeneous regarding drought threats. The eastern part of the catchment is classified as more sensitive to water scarcity because of its exposure and vulnerability, as irrigated crops are rooted in these areas. Since 2011 (Regional Decree of 24 January 2011), the entire Vilaine catchment is no longer classified as a water-sensitive area (in France, ZRE, zone de repartition des eaux). In France, a 'water-sensitive area' refers to an area where water resources are insufficient compared to water uses, and the area is thus considered to require special protection regarding low-flow water levels. In water-sensitive areas, abstractions other than for drinking water are limited between 1 April and 30 October at their current level. Small dams may be permitted only if they have no impact on low-flow rates. Because the Vilaine catchment is no longer considered a 'water-sensitive area', it is no longer possible to constrain water uses permanently in the Vilaine area (although water use restrictions may be put in place during dry years, i.e. in below mean situations). Recent water management measures in the Vilaine claim that the catchment should again be registered as a 'water sensitive area' (see Sect. 6.3.3 for a detailed description of water management in the catchment).

\subsubsection{The Arzal Dam}

\subsubsection{One Initial Objective: Regulating the Risk of Floods}

The Arzal dam (Fig. 6.3) is located at the mouth of the Vilaine catchment, just above the outlet of the river to the Atlantic Ocean (Fig. 6.2). It was built in 1970 to isolate the lower reaches of the river basin from the ocean and block the tidal flow, which previously travelled inland as far as the city of Redon and could aggravate flooding in the valley when floods in the Vilaine River occurred simultaneously with a high tide.

\subsubsection{An Opportunity: A Reservoir with Multiple Uses}

In addition to regulating the risk of floods, the dam also allowed the creation of a reservoir of $50 \mathrm{Mm}^{3}$ of freshwater, stretching up to $80 \mathrm{~km}$. A water supply 


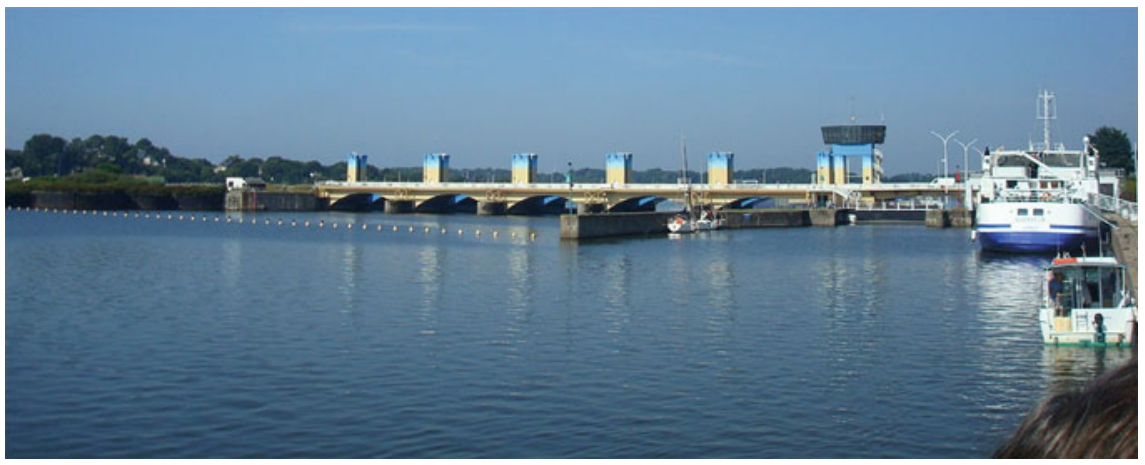

Fig. 6.3 The Arzal dam (Source IAV, with authorization)

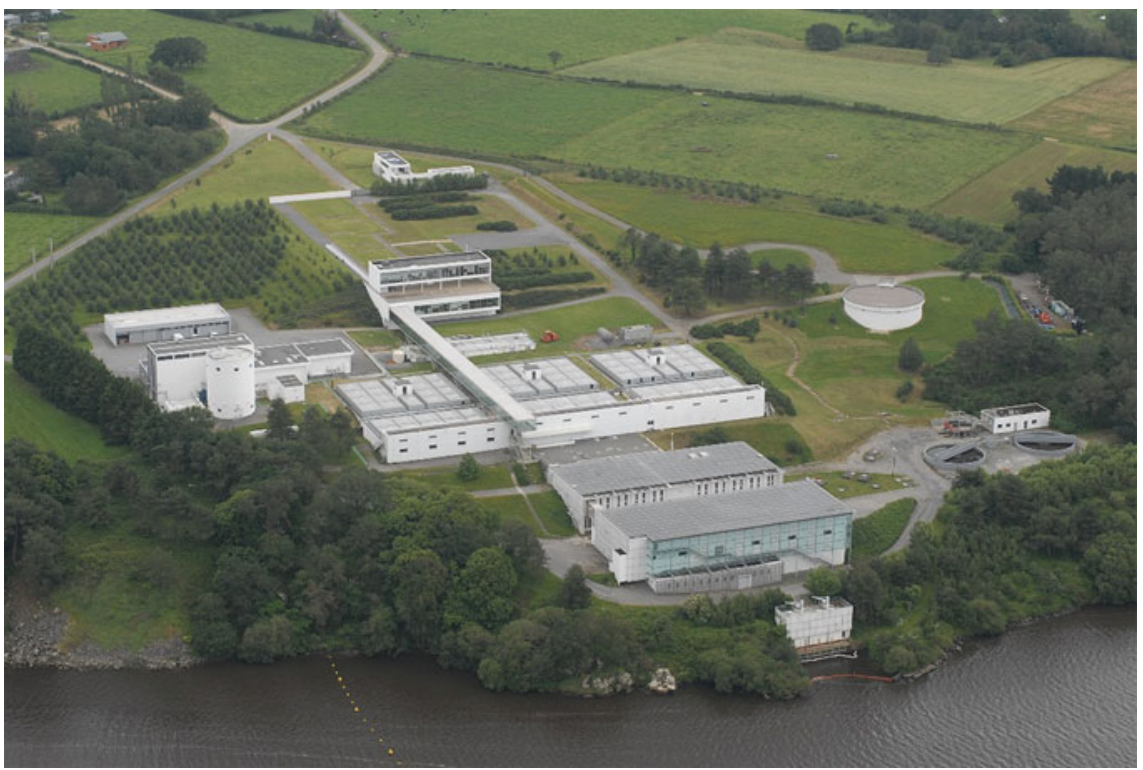

Fig. 6.4 The drinking water production plant (Drezet at Férel) that treats the water from the Arzal reservoir (Source IAV, with authorization)

treatment plant (Drezet at Férel, Fig. 6.4) was inaugurated in 1972, with a production capacity of $30,000 \mathrm{~m}^{3}$ of drinking water per day, corresponding to an instantaneous pumping rate in the reservoir of $1600 \mathrm{~m}^{3} / \mathrm{h}$. Today, its maximum production capacity has been increased to $90,000 \mathrm{~m}^{3}$ per day, corresponding to an instantaneous pumping rate in the reservoir of $4800 \mathrm{~m}^{3} / \mathrm{h}$. The water plant supplies 15-20 $\mathrm{Mm}^{3}$ of freshwater annually. Up to 1 million inhabitants are supplied with drinking water by the Arzal reservoir during the summer season. 


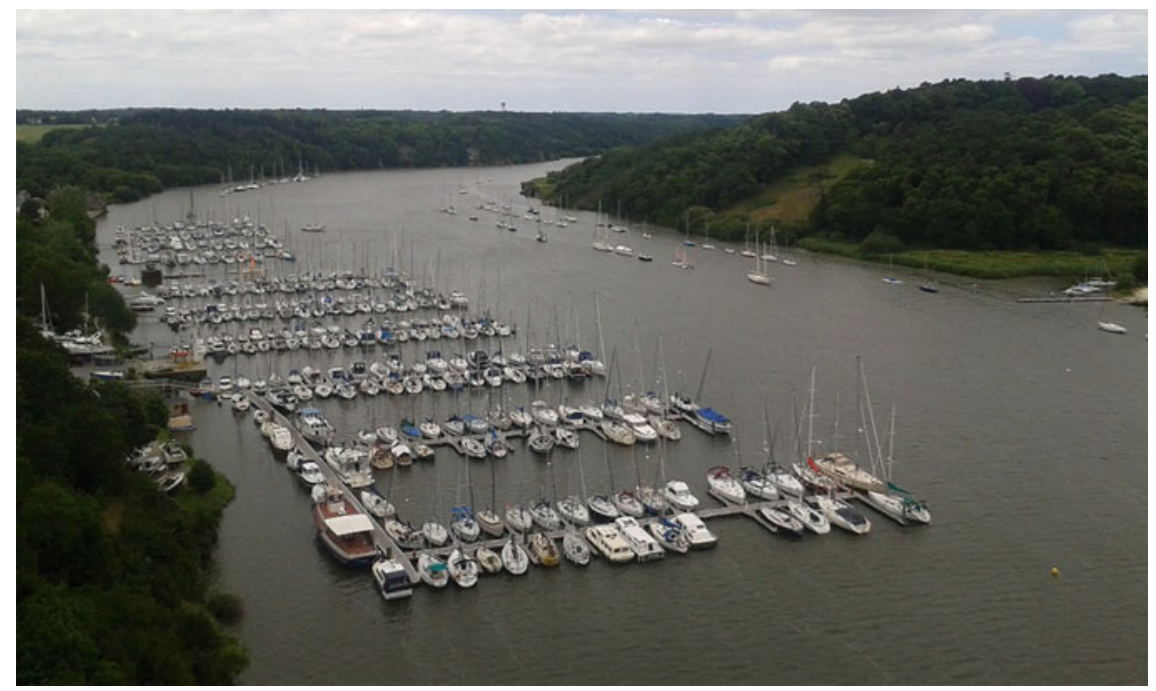

Fig. 6.5 A yachting marina in the Vilaine River before the Arzal dam (Source La Jeunesse I., with authorization)

The Arzal dam also encouraged the development of new recreational activities such as yachting. Sailing is now highly developed in the area (Fig. 6.5), with an average of 18,000 boats crossing the dam per year, and approximately $85-90 \%$ of boat crossings occurring during May to October, thus, during the low-flow period (see Sect. 6.3.1). Sailing and fish passages have, however, an influence on the quality of the water in the reservoir. Freshwater quality in the reservoir can be

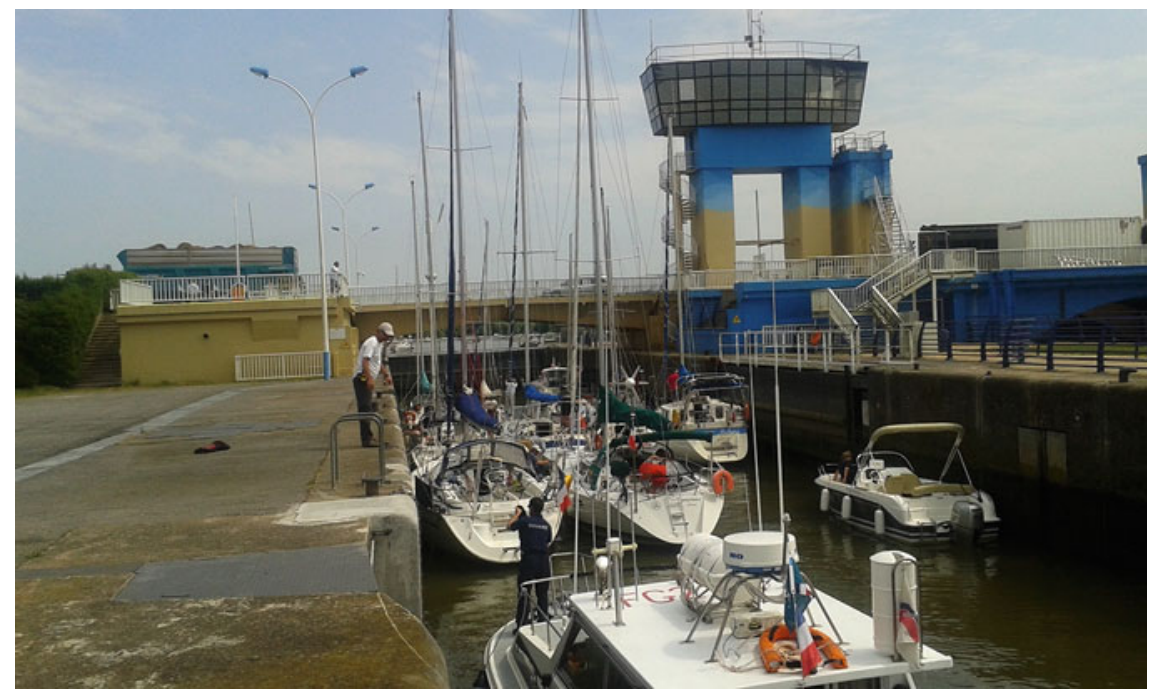

Fig. 6.6 The lock of the Arzal dam (Source IAV, with authorization) 
affected primarily by salt water intrusions. They occur primarily when the lock is operated for navigation (Fig. 6.6). They are usually handled by a system of syphons that automatically evacuates salt water from the reservoir to the estuary. Because the most significant inputs of salt water to the reservoir occur when boats pass through the existing lock of the dam, navigation can be restricted during the summer. Management rules with restrictions on the time schedule and number of lock openings can thus generate conflicts, especially during the summer high season for recreational sailing.

Today, the Arzal dam consists of five elements: an unsinkable dike, a set of five sluices, a lock, a syphon and a fish passage.

\subsubsection{Pilot Measures Implemented Within the DROP Project}

The Arzal dam and its reservoir are managed by IAV, the practice partner of the DROP project for the Vilaine case study. IAV is an EPTB (see Sect. 6.2.1), which means that it is a French public organization for the cooperation of local authorities (regions, departments, municipalities, etc.) towards the development and management of rivers in the geographical context of a river catchment or sub-catchment. IAV faces challenges related to salt water intrusion and reservoir management during the low-flow season, when both water quantity and water quality constraints apply on the management of the dam. As mentioned earlier, salt intrusions in the reservoir mainly occur when boats pass through the lock at the dam. When water inflows tend to be the lowest, recreational activities, including sailing, are generally at their highest level (because it involves the summer period), and lead to a peak of salt water intrusions in the reservoir, which can affect freshwater quality and, thus, quantity. To prevent salt intrusions, syphons have been installed upstream of the dam to pump the contaminated water from the reservoir back to the Atlantic Ocean. However, this system causes a significant loss of resources: approximately, 300,000 $\mathrm{m}^{3}$ of freshwater are evacuated every day from the reservoir, compared to an average of only $10,000 \mathrm{~m}^{3}$ of salt intrusions. In addition, the syphons are not $100 \%$ efficient: some brackish water still enters the reservoir, and salinity peaks are regularly observed in late summer each year. Moreover, this system leads to losses of substantial quantities of freshwater, which, during prolonged periods of drought, may aggravate the problem of multiple uses of the reservoir and impact the freshwater supply.

Currently, the only way to limit salt water intrusions and, consequently, water losses from pumping is to place restrictions on the use of the lock in summer. The two principal strategic management objectives during low-flow periods are (i) to ensure a level in the Arzal reservoir that is adequate to permit all uses and (ii) to keep saltwater out of the Arzal reservoir as much as possible to preserve freshwater quality and guarantee the drinking water supply. However, these management objectives are not always satisfactory because they may result in restrictions in the use of water, which may not be fully accepted by other water users in the catchment: a preventive rise in water levels to supply summer water needs may result in flooding the wetlands during the hay harvest, forcing IAV to pay financial 
compensation to farmers; moreover, restrictions in the use of the lock at the dam during summer periods are seen by boat owners as an infringement of their freedom of navigation, a practice especially resented by boaters, as they invest money to maintain this activity.

This context has prompted IAV, over a long period of time, to consider the implementation of new solutions. The DROP project, comprising interactions with other practice partners managing freshwater reservoirs and with experts in governance analysis, was an opportunity to improve the reflections that were initiated in the course of optimizing the management of the reservoir during drought periods. Concretely, two main pilot measures were taken during the DROP project, a new lock and drought forecasting:

(a) The implementation of a new lock at the dam

IAV has worked on developing a new and innovative lock at the dam to prevent salt water intrusion when boats cross the dam. Significant efforts have been put into designing this new lock: preliminary and feasibility studies, 3D hydraulic modelling, and even a physical model at the 1/12 scale. Currently, all preliminary studies are finished, hydraulic and physical models have been calibrated, all simulations have been completed, design plans have been achieved, and a consolidated estimate of the cost of the project has been conducted.

(b) The development of drought forecasting and risk management tools

In parallel, IAV has been working with the IRSTEA research centre, which is also a partner of the DROP project, to develop a modelling system to forecast inflows to the reservoir during the low-flow season and help anticipate critical situations to ensure better drought risk management. The system incorporates weather information into a hydrological forecasting model and translates the results into a graphical representation of the drought risk. Future possible weather scenarios over the Vilaine catchment can thus be considered and transformed into river inflows all the way upstream to the dam. The graphical representation of the drought risk provides a visual assessment of the risk of being below given critical low-flow thresholds in the next weeks or months, both in terms of flow intensity and duration (i.e. mean flow and number of days below each critical threshold, respectively). This risk assessment visualization tool aims to help the managers of the dam in deciding whether to release water from the reservoir and on how to operate the corresponding dam components. It can be integrated into the various reservoir operations and management rules necessary to fulfil its multiple operational uses, connecting the utilities in a pre-operational framework. The tool is based on the development of a global forecasting chain, including the development of weather scenarios combining a short-term meteorological forecast ( 9 days), a long-term meteorological forecast (3 months) and an analysis of past events over the last 50 years. This pilot answers to the needs of drought alert tools, as also promoted by the national methodological guidelines presented earlier (Sect. 6.2.3). 


\title{
6.3.3 Water Management in the Vilaine Catchment
}

\subsubsection{The Main Instrument Devoted to Water Management in the Area: The SAGE Vilaine}

\begin{abstract}
A SAGE (Fig. 6.1, Sect. 6.2.2) is in force in the Vilaine catchment area. It is the largest in area of any SAGE in France. In terms of territorial governance, it involves two regions (Bretagne and Pays-de-la-Loire), six departments (Ille-et-Vilaine, Morbihan, Loire-Atlantique, Côtes d'Armor, Mayenne, Maine-et-Loire) and 534 municipalities. An initial water management plan was enacted in 2003. It was revised in 2015 and now includes a plan for sustainable management of water resources and aquatic environments (PAGD), as required by the water law of 2006.

In general, issues regarding the management of the Arzal dam are closely related to the dynamics of the water levels in the reservoir and in the river reaches influenced by the reservoir. This linkage plays an important role in the water governance of the whole Vilaine catchment and, particularly, of the lower part of the river basin. Three specific management issues are (i) the siltation problem in the estuary, (ii) the management of agriculture and hunting in wetlands and (iii) the salinization of freshwater related to the passage of the dam by boats. Following the conflicts induced by the management of the dam, IAV proposed to build new committees to represent all stakeholders concerned by these issues, with two initiated directly by the SAGE Vilaine: the estuary committee and the Natura 2000 committee. The objectives of these committees are to enhance solidarity among water users sharing the same resources and to improve coherence between general water resources management and drought control measures.
\end{abstract}

\subsubsection{The Estuary Committee}

Since the creation of the dam, the salinity gradient and the transfer of sediments in the river have been heavily modified. The estuary is facing rapid siltation, with no satisfactory solutions implemented at the moment. These ecological modifications have impacted fishing and shellfish farming both in the estuary and in the river. The rapid siltation prompted the creation of an Estuary Committee in 1999, which, as a consultative body, aims to specifically address the issue of the silting of the estuary in the Local Water Commission (LWC).

\subsubsection{The Natura 2000 Committee}

The marshes of Vilaine and Redon form nearly 10,000 ha of alluvial grasslands upstream from the Arzal dam. These marshes were, for the most part, the inner estuary of the Vilaine until the construction of the Arzal dams. These marshes belong to the European site network Natura 2000, which aims to preserve 
endangered biodiversity in Europe. As explained earlier, the regulation of the water level of the Arzal reservoir may induce flooding in the upper wetlands during the dry season. The Natura 2000 committee represents hunters, naturalists and some farmers with concerns about the periodicity of the flooding of those natural areas. The committee was created at the same period as the site network and contributes actively to the SAGE Vilaine.

\subsection{Assessment of Drought Governance Qualities}

In this section, we present our findings regarding the observations on the four qualities of the governance assessment tool, namely, extent, coherence, flexibility and intensity, assessed on the five governance dimensions of the matrix that forms the framework of the GAT (Bressers et al. 2013a, b, c).

To the greatest extent possible, this analysis distinguishes between (a) water management and governance as such and (b) governance related to drought adaptation. These elements do not have the same aims. Water management is part of an integrated system that is implemented in almost all decision-making bodies. Adaptation to drought is mainly restricted to water level regulation and the management of water crises during drought.

\subsubsection{Extent: Large for Water Management and Limited for Drought Management}

The levels and scales dimension has a truly supportive basis in the water management of the Vilaine catchment. The administrative management of the entire Vilaine catchment has a wider extension, with scales ranging from the European level at the top through the national, regional, departmental, and intercommunal levels and all the way down to the communal level. As for the SAGE Vilaine (Sect. 6.2.2) and the management of the Arzal dam and its reservoir by IAV, the involvement of representatives of each level is not the same: three departments (Morbihan, Ille-et-Vilaine, Loire-Atlantique, Fig. 6.2) are more involved in the decision-making process than the others. This can be explained by the fact that the other three departments within the Vilaine catchment (Côtes-d'Armor, Mayenne, Maine-et-Loire, Fig. 6.2) are less affected by the management of the Arzal dam. However, the whole catchment of the Vilaine is involved in the local water commission (LWC), representing six departments within two regions. Drought management relies on the same organization as that of water management, and, for that reason, the levels and scales that are potentially included are as large as the ones involving water management. However, water crisis management is situated at the national level. 
Regarding actors and networks, users and managers have shown mutual trust thanks to frequent formal and informal meetings driven by IAV for discussing shared issues. There is also a strong awareness of the decision-making processes in water management. None of the interviewed actors expressed the feeling of being excluded from any decision-making process. IAV has thus built a strong network, involving the most relevant actors within the territory, and has become an institution with remarkable political involvement and influence. However, concerning drought management, we can observe that there is no network of actors specifically dedicated to address drought management at any scale except for crisis management at the national level, as mentioned earlier.

The LWC and the SAGE enable any issues related to water management to be addressed. As a result, the problem perceptions and goal ambitions can potentially have a broad extent provided that all issues are addressed. However, this is not yet the case. Before the DROP project, for instance, the impacts of climate change on drought frequency and intensity had never been considered a topic to be discussed by the LWC. In fact, drought is not a hazard mentioned frequently in discussions related to water management. Several considerations can explain this observation. First, the area is a wet region and, even though it has seen severe drought events in the past, they remain rare. Additionally, the several dams that exist along the Vilaine River, including the Arzal dam located at the outlet of the catchment, are already seen as infrastructures that tackle the problems of water scarcity. This is observed even though some eastern parts of the catchment, which are more concerned by intensive agriculture practices, are already experiencing water scarcity. Moreover, drinking water is the central issue for the manager of the Arzal dam. The perceptions of the impacts of climate change and its consequences on the frequency and severity of drought events are still largely relegated to the State administration at the national scale, and, locally, are mainly oriented towards crisis management.

The main instruments for regulating water use are integrated in the SAGE Vilaine with a general strategy concerning regulations, incentives and communication. However, and this is the case for all the country, even during drought periods, the price of drinking water cannot be considered an economic adjustment tool. This is because the national legislation in France ("drinking water pays for drinking water") imposes an independent budget. The price of water is fixed and indexed to the cost of its management. It cannot be used as a regulation instrument in situations of water scarcity. For drought concerns specifically, one can state that there is a restricted extension related to strategy and instruments. This can be explained by the drought adaptation strategy developed nationally. Since the frequency of drought events is not high in the Vilaine catchment, it is not classified as a quantitative 'water sensitive area', as mentioned earlier. For this reason, this area is considered not to require enhanced protection against drought and water scarcity. This national context does not encourage measures to anticipate drought induced by climate change. This particularly affects wet regions, where drought awareness is usually very low. In the context of the DROP project, it must be highlighted that IAV seeks solutions for drought adaptation (see Sect. 6.3.1), namely, by 
considering the implementation of drought forecasting and risk assessment tools. This represents a necessary initial step towards local preparedness for drought and local awareness (Richard 2013) of the possible impacts of climate change on drought. It is also a first modelling phase before initiating a common adaptation strategy resulting in adaptation measures.

IAV clearly has technical resources and responsibilities for the management of the Arzal dam and its reservoir. The objectives of the two pilot measures (Sect. 6.3.1) show the investment of resources by IAV towards the aim of managing a multi-use reservoir. However, information about the responsibility of each stakeholder remains unclear: the water users (especially farmers) are not always fully aware of the quantity and the quality of the water they are using. Local governments, who are responsible for various controls on water withdrawal, are not often aware of their duties. Concerning drought management, the regulation from the SDAGE indicates the priority to be given for various water uses in the event of drought. However, it does so at a very local level, while water policy (e.g. policy on pumping and pollution control) is clearly under the responsibility of the State services (national level). Thus, the extent of resources and responsibilities is positive, but the distribution of resources and responsibilities could be more clearly addressed.

\subsubsection{Coherence: Agreement on the Priority to Give to Drinking Water}

IAV has a central role in terms of cohesion among stakeholders within the Vilaine catchment. All interviewed actors agreed that having a single interlocutor, IAV, works well and facilitates dialogue. However, as far as the drought management issue is concerned, coherence between levels and scales has not been fully achieved: some actions are implemented coherently (e.g. interconnection between drinking water networks), but the integration of the climate change perspective lies mainly in the hands of the State services and remains inside the IAV through the coordination of the SAGE Vilaine.

Since the reform and decentralization of the role of the State in the 1990s, the State has had little decision-making power over water management issues. The decentralized services are managing water resources and making decisions within the catchment scale. They are under the authority of the Prefect, who implements the policy of the State under its regulatory and technical aspects. However, there is a lack of consistency between these government services in the Vilaine territory. Difficulties in coordinating interdepartmental relations have been cited during the interviews. At the same time, the actors in the Vilaine catchment are clearly used to working together, formally and informally. The Vilaine Committees (see Sect. 6.3.2) have been very successful at making people collaborate, and their 
success supports the coherence of actions relevant to water management at the catchment scale.

Regarding the common perception of problems and goals ambitions, the very positive consensus on water management can be assessed by the fact of general acceptance, i.e. the acceptance, by all stakeholders representing the various water uses, of the priority given to drinking water. The availability of water provided by the dam supports this priority. However, the perception of the risk of drought and the potential impacts on freshwater availability is almost absent for the majority of stakeholders. This can be explained by the more frequent flooding issues in the area, which was, in particular, observed during the period of interviews in connection with the floods that occurred in Brittany early in 2014.

As there is no comprehensive information about the quantity of water withdrawn by all water users, water managers are not really able to implement a truly coherent policy by soliciting coherent strategy and instruments. Moreover, the SAGE is a compromise between stakeholders, and some of them are more organized than others. As a result, some interests are taken into account more than others, especially those related to the drinking water supply. Furthermore, despite the work being conducted to integrate agricultural regulation in the WFD, agricultural policy is still declared by local stakeholders to be too thoroughly disconnected from the other instruments in the catchment due to the CAP (Common Agricultural Policy), which is decided at the European level and is not linked directly with water policy at the local level. A coherent implementation of strategy and instruments is, thus, hard to find for water management as a whole in the area and even harder for drought management.

The responsibilities of each actor with regard to the WFD are not obvious. Most actors think that the responsibility lies mainly in the hands of the State services as represented by the Water Agency. Most water users are not considering the link between their activities and water resource management. In fact, the LWC's responsibility is to be a decision-making authority, but it has neither the financial nor the technical means to implement decisions, so it has no resources to implement the plan of actions proposed. At the scale of the Arzal dam and its reservoir, the financial and technical aspects are provided by the IAV. At a more local level, we observe that some municipalities do not have the means to finance $20 \%$ of the budget for the implementation of local projects related to water even if the subsidies, as those coming from the Water Agency, cover the remaining $80 \%$.

\subsubsection{Flexibility: Limited by the Emergence of Multiple Structures Partly Compensated by the Number of Instruments}

Most decisions about water management are made at the scale of the catchment and sub-catchment areas due to the decentralization of the role of the State. This 
situation can lead to a lack of consistency among the different services. In general, the State lacks the flexibility to better coordinate crosscutting issues. The current structures managed by the State work with a top-down approach. The two different speeds of operation and decision-making, the speed of the State and the speed of the LWC, represent a cogent reality for the LWC. The meetings held by the LWC are very pragmatic and achieve high goals in terms of water management, while State services struggle to advance equally rapidly and anticipate the coordination needs of stakeholders. At the catchment level, the LWC makes substantial efforts to integrate the different levels and scales of decision-making.

Actors and networks are all represented in the LWC, and there is real flexibility at the catchment level to allow the creation of committees devoted to special areas and topics. However, there is currently no committee for drought management and adaptation issues. Moreover, it appears that the priority given to drinking water is not flexible, as the quantity of water dedicated to this use needs legally to be delivered by IAV.

For the Arzal dam, there is little flexibility of problem perceptions and goal ambitions because of the importance given to the drinking water service. However, at the level of the catchment scale, the interconnection between the various drinking water networks allows some flexibility in water management even if it may not be sustainable on a long-term basis. Considering drought management because this is an issue that is not easily addressed by most of the actors, we can state the hypothesis that there is little flexibility in problem perceptions and goal ambitions related to drought.

At the local scale, there is a certain flexibility in adapting strategy and instruments. A concrete example is the change of the name of the Natura 2000 Commission initiated by the Mayors of the municipalities of the Vilaine catchment: they changed its name to "Vivre les marais" ("Living the marshes") as a way to gain more local support for the initiative. Additionally, "regional doctrine" for irrigation has been stated in the SAGE for the eastern areas of the Vilaine catchment, which are more vulnerable to low flows, under which the financing of water reservoirs is allowed only if there is no impact on the river flow during low-flow periods. This creation of new instruments seems, in fact, to be more flexible than the national policy. However, drought is not yet integrated into most of the existing instruments. Drought issues still rely on crisis management and not on anticipatory measures. However, given the impacts of low flows and drought periods on the various water uses of the Arzal reservoir, and considering the two pilot measures being developed by IAV, the flexibility of the multi-use reservoir is expected to be enhanced by decreasing the impact on water quality of the passage of the lock by boats and improving low-flow risk management. These measures would also imply a more favourable adjustment of the level of water in the dam for the wetlands during the dry periods.

The decentralization of responsibilities is currently an important issue in France due to a new governing body for the management of aquatic environments and flood prevention (GEMAPI), which will be transferred to local governments. Its creation is interpreted differently according to actors for the impact on 
responsibilities and resources. For some, the GEMAPI will bring more coherence because it will allow good structures to be set up; for others, the municipalities would be forced to take on too many duties without sufficient financial means to implement the management measures. Considering the issue of drought adaptation, here again, the rigidity of responsibilities regarding crisis management does not allow flexibility in the implementation of drought adaptation measures.

\subsubsection{Intensity: Awareness of Drought Issues Induced by Climate Change Is Low}

The intensity of activation of several levels and scales is important in the Vilaine catchment for water management but not for the possible increase of drought frequency or intensity due to climate change. At the catchment scale, IAV has a strong impact in terms of preserving water supply and implementing some specific measures. However, IAV does not yet have the capacity to propose solutions for other water uses during drought periods. Furthermore, the low level of drought awareness among most of the actors is an obstacle that precludes the enhancement of the intensity with which levels and scales are recognized and implemented in drought adaptation strategies.

The intensity of one actor, IAV, is maximally strong in the lower Vilaine River area. It drives a network represented by all the representatives of water uses within the catchment and succeeds in making people work together throughout the area. This is mainly due to the coordination activity of the SAGE Vilaine, linking water users and water managers at the entire catchment scale surrounding the IAV. However, as the place of IAV remains too central, it can be interpreted also as indicating a certain vulnerability of the network.

Regarding drought perceptions and goal ambitions, we observe that awareness has gradually increased, although the anticipation of drought events is only effective in sensitive areas located on the eastern part of the catchment. Therefore, this awareness does not directly concern the Arzal dam and its reservoir. Only drought crisis management, based on critical observed low-flow conditions, is planned and integrated within the dam management rules driven by IAV. We can also emphasize that drought is seldom mentioned by stakeholders in relationship to climate change impacts. Up to now, climate change has neither been discussed within the LWC nor considered a threat to the sustainability of the production of the freshwater resource in the whole catchment. Only recently, at the end of the DROP project, has it received more attention in the management of freshwater in the Arzal dam.

In France, strategy and instruments for water crisis management are well defined at the State level. At the catchment scale, the SAGE regulation can provide 
additional guidance, such as the volumes of surface water bodies or groundwater to be allocated to each category of users. Regarding the Arzal dam, the abundance of water in the reservoir and the priority given to drinking water are sufficient to make it unnecessary to dedicate extreme effort to drought adaptation strategies. From a different perspective, several stakeholders around the Arzal dam mentioned during interviews that there is a need for groundwater monitoring to assess not only the state of the resource but also the level of consumption. In fact, there is actually a lack of groundwater surveys in the catchment area. There is neither an assessment of groundwater tables nor knowledge about the number of private wells and the associated withdrawals at critical periods. Thus, even if the issue of drought is receiving increasing consideration, the lack of effective instruments could impede the rapid development of a strategy of adaptation to droughts.

\subsection{Overview and Visualization of the Results of the Analysis}

\subsubsection{The Priority Devoted to Drinking Water Production}

In the Vilaine River area impacted by the management of the Arzal dam and its reservoir, one can say that the need to produce drinking water is paramount, and other activities related to water are placed at a second priority level. All users of water resources and local municipalities are aware that resource protection is crucial, but many of them do not want to bear the consequences of a restriction on water use in their territory-the "not in my backyard" syndrome. The need to produce drinking water is essential, but it also requires concessions. In the Arzal area, the only adjustable variable considered is the water level in the reservoir and, still, all stakeholders and managers agree on the priority to be given to the protection of water resources for producing drinking water. Trade-offs are only accepted when water scarcity becomes obvious, as in sensitive areas in the eastern sub-basins of the Vilaine River.

The observations described in the previous section lead to the general conclusion that the governance context for drought adaptation policies and measures for the case of the Arzal area of the Vilaine River can be considered as moderately positive. This general conclusion is obviously relative to the observations collected during the interviews that were carried out in 2013-2014 and may evolve with time. The following matrix seeks to represent the supportive, neutral and restrictive elements of the drought governance analysis provided (Fig. 6.7). 


\begin{tabular}{|l|c|l|l|l|}
\cline { 2 - 5 } \multicolumn{1}{c|}{} & \multicolumn{4}{c|}{ Governance Criteria for Drought Management } \\
\hline Governance dimensions & Extent & Coherence & Flexibility & Intensity \\
\hline Levels \& Scales & & & & \\
\hline Actors \& Networks & & & & \\
\hline $\begin{array}{l}\text { Problem Perceptions \& Goal } \\
\text { Ambitions }\end{array}$ & & & & \\
\hline Strategies \& Instruments & & & & \\
\hline Responsibilities \& Resources & & & & \\
\hline & & & & \\
\hline
\end{tabular}

Fig. 6.7 Visualization of the main conclusions of the assessment of the drought governance context in the Arzal dam and reservoir, Vilaine catchment, France

\subsubsection{The Interplay of Stakeholders and Their Motivations, Cognitions and Resources}

The recognition of the needs for drought adaptation in France as a whole is strong at the national level, whereas it appears to be in only an extremely early phase in this northwestern part of France. The Governance Assessment Tool, based on Contextual Interaction Theory (see Chap. 3), enables a comparative analysis of key governance factors representing the freshwater use as the main water use. The governance context influences these processes through its impact on these actor characteristics: the drivers of processes are ultimately people, representing sometimes themselves, but often organizations or groups and themselves driven by their motivations, cognitions and resources.

In the Vilaine catchment, except for emergency measures, there is no global plan set up to manage drought vulnerabilities induced by climate change. The current situation of low drought risk perception, compared to a more significant flood risk perception, is explained by a lack of drought risk awareness, due to the absence of critical drought events in the past years in the region and the lack of a culture of drought forecasting and risk communication. However, it is expected that as drought perceptions are raised, drought adaptation measures can rapidly be designed and implemented by the efficient, existing water governance for freshwater in the basin, which is supported by a dense stakeholder network driven by IAV.

In the territory affected by the management of the Arzal dam, a key issue is that the acceptance of climate change (cognitions) as a reality or at least as a relevant issue for the stakeholders involved is very weak. This is identified as a major problem and a root cause for the low degree of openness towards adaptation (motivation). However, plain interests also play a role in this low motivation of 


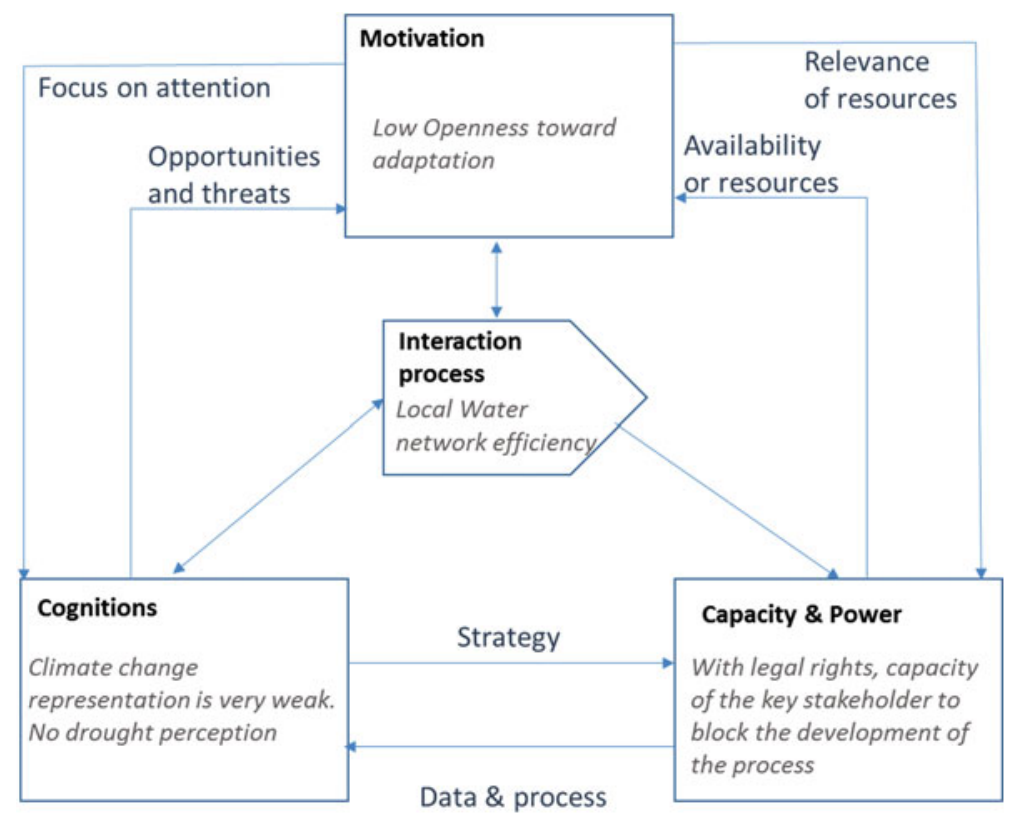

Fig. 6.8 Contextual interaction theory applied to the Arzal dam management in the Vilaine catchment, situation during interviews (2013-2014)

some of the users. With their legal rights (resources), they are also in the position to block the development of the process, at least until a higher level of awareness (cognitions) has been developed (Fig. 6.8).

However, after our diagnosis of the intensity of perceptions of local challenges for water use due to the impacts of climate changes, although the role of strong resources in blocking the development of adaptation measures could be considered highly negative, that is just a matter of interpretation. If the answer is "strong", we must recognize that the influence on the dependent variable that the score is very negative. This characteristic of the interaction process can also be highly supportive. Perhaps the story for Vilaine, as also formulated in words, is that all three main factors now have a negative influence on the progress of adaptation. However, when change occurs, most likely a change from cognitions (more awareness), to motivation, such change would have a positive influence on drought adaptation. Thus, the same strong resource position that is now capable of blocking progress would then become a productive position in the development of adaptation measures. As a consequence, relatively rapid change is not impossible and even possible. To represent this possibility, Fig. 6.9 describes the process induced by an improvement of local climate change awareness.

Finally, the last DROP meeting with practitioners, planned in the presence of French national observers (ONEMA, The French National Agency for water and aquatic environments) and held in June 2015, permitted an overview of the situation 


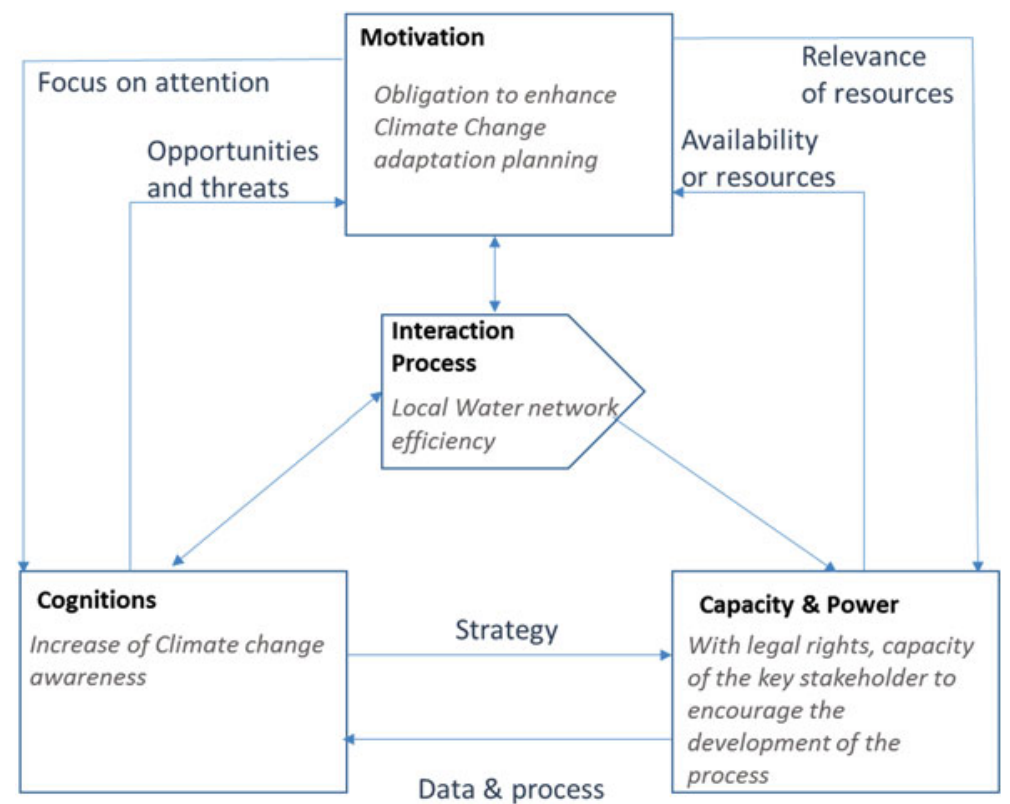

Fig. 6.9 Contextual interaction theory applied to the Arzal dam management in the Vilaine catchment resulting from climate change impacts awareness (scenario)

of drought awareness after one year. A significant change was noted in the consideration of the possible impacts of climate changes on drought frequency by IAV. It is not possible to affirm that this change was due to the work performed during DROP, but one can state that a supportive process facilitating the development of drought awareness is ongoing.

\subsection{Conclusions and Case-Specific Recommendations}

The governance team of the DROP project concluded that the strong network driven by IAV for drinking water management of the Arzal reservoir in the lower Vilaine River catchment and for the implementation of the SAGE management plan can also be used for drought management, even if this currently is not the case. If the focus is placed on setting up drought policy and drought adaptation plans, the structure of the system of the levels and actors in the whole Vilaine catchment will be available for its implementation. It is expected that it is the overall high availability of water as well as the common priority given to drinking water by these actors that currently forbid the implementation of measures for drought adaptation in the Arzal reservoir area except in those sub-basins where water scarcity is already obvious but where the use of water from the Arzal reservoir is not a concern. 
Additionally, it must be noted that the recent reforms related to local governments introduced uncertainty in the actor network. In particular, this consideration is linked to the fact that the departments are not supposed to be involved in water issues in the near future. Additionally, there could be a change through the agency of the recent law on the modernization of public action (MAPAM), which would lead to a reaffirmation of everyone's skills and formal competences at the local level.

The matrix presented in Fig. 6.7 should be considered as a "photograph" of drought governance at the period of the interviews rather than an established state of drought governance for the Arzal dam and reservoir. Some recommendations have been proposed to enhance drought resilience through adjustments to current water governance in the Vilaine catchment. These recommendations are based on comparing the Vilaine governance context with previous knowledge from the Governance Team of the DROP project on other water management systems, including the ones investigated in the other regions studied in the project.

Taking into account the main supportive elements of the water governance in the Vilaine catchment, i.e. the ability to put together a strong network of actions to develop an integrated water management at the basin scale, the recommendations presented below are oriented towards a better incorporation of more "drought concerns" into the current governance scheme. They are also devoted to enhancing intensity and flexibility within the water governance framework. Five main recommendations have been formulated as follows:

\subsubsection{Create a Task Force Dedicated to Climate Change Impacts on the Territory, Within the Existing Water Management Network, to Raise Awareness About Drought}

In the case of the Vilaine site, as with other sites of the DROP project, there is a clear lack of sensitivity towards drought issues, most probably due to a highly favourable situation in terms of water availability in the area until the present time. An outreach effort is necessary to strengthen the awareness of water users and water managers of drought and adaptation measures that can be implemented in the area. Such an effort could first target a better understanding of the impacts of climate change in the specific territory of the Vilaine catchment relative to its own climate variability and vulnerability to drought and water scarcity. The efficient network of actors in water management, which is one of the strengths outlined in the case of the Vilaine catchment, could then be fruitfully mobilized around drought issues and around water scarcity more generally.

In this context, the LWCs driving the SAGE have a special role to play in mobilizing human and financial resources and interfacing with local actors. Geographically defined or topical committees can play a special role by tailoring 
the building of knowledge to specific challenging situations, e.g. estuaries, Natura 2000. Moreover, the creation of a task force dedicated to climate change impacts is recommended at the LWC level to keep this initial interest more closely focused on local needs and perceptions.

This sensitization of the actor network in water management towards climate change issue would enable increased awareness among all stakeholders regarding the potential impacts of climate change on water and water-related activities in the Vilaine catchment.

\subsubsection{Enhance the Knowledge of the Water-Related Impacts of Climate Change in the Specific Vilaine Catchment}

The task force mentioned in the preceding section would collect all the data related to the impacts of climate change on the territory of the Vilaine. These data should be used to identify and, if possible, quantify drought issues related to climate change and translation impacts in terms of water availability as well as their consequences for current and potential future water uses.

On the basis of this state-of-the-art data collection, the task force should also promote knowledge of climate change's impacts on the territory by undertaking specific studies targeting the main water uses of the catchment. Three main water sectors could be investigated: (i) agriculture, (ii) drinking water supply and (iii) tourism (including boating for the Arzal dam). Such a development would require a better knowledge about the interconnections between surface and underground water resources and could be supported by the monitoring of withdrawals, which has not yet been initiated. Moreover, it will be important to link flood- and drought-associated risks so that the solutions for flood prevention do not worsen drought situations and vice versa.

\subsubsection{Develop a Strategic Foresight Analysis to Identify the Potential Types of Drought Situations in the Basin and the Means to Better Prepare Local Stakeholders to These Situations}

Going a step further, enhanced knowledge about the impact of climate changes on the Vilaine catchment could be promoted by developing strategic foresight studies that would analyse future scenarios and help stakeholders to better anticipate the consequences of human activities on the ecological status of the basin and the quality of freshwater.

Within the SAGE instrument, an initial identification of sensitive areas related to low-flow water was conducted, especially for areas located at the eastern part of the 
Vilaine catchment, which led to the development of specific rules. A comprehensive approach could be undertaken regarding the sensitivity of the area to the potential impact of drought related to climate change. This could be extended to the whole area of the catchment and contribute to establish a typology of geographical sectors and activities sensitive to climate change impacts. A more accurate assessment of the vulnerability of these sectors and territories, i.e. a precise evaluation of the consequences of drought and water scarcity for each type of activity and each location in space, would allow stakeholders to better anticipate the impact of a reduction of water resources on their activities.

\subsubsection{Support the Development of Integrated Drought and Water Scarcity Management}

Finally, a foresight analysis could lead to the identification of the most efficient measures to be implemented to take into account the potential climate change impacts on the Vilaine catchment into the economic activities of the water uses. This would support the development of integrated drought and water scarcity management, considering drought impacts on surface water as well as on groundwater and soil moisture.

To this end, a drought management and adaptation plan could be elaborated to address the impacts not only on surface water but also on soil and agricultural practices. In fact, the most recent droughts in the region were agricultural droughts. As far as water is concerned, a more comprehensive and effective policy aimed at reducing water consumption and withdrawals can be recommended. However, anticipatory drought management relies not only on the regulation of water level and withdrawals but also on techniques that, both, survey and help to keep moisture in the soil, which is of paramount importance for agricultural activities.

By identifying in advance drought adaptation measures to be implemented, anticipatory vulnerability assessments of surface water, groundwater and soils would complement the only measures of crisis management presently observed in the catchment regarding drought issues.

Drought adaptation plans could also be related to other planning documents, such as the one related directly to climate change, which usually relies upon other types of actors (i.e. SRCAE instrument cited in Sect. 6.2.2). Joint actions between the LWC and those actors already involved with climate change studies are highly recommended. 


\subsubsection{Sharing Low-Flow Forecasts with Reservoir Management Interested Parties}

One of the aims of the DROP project in the Arzal dam site is the development of a tool for forecasting low flows and enhancing water management at the reservoir. Sharing information is essential to ensure that the management of the reservoir meets the standards of openness and transparency. It can also engage early cooperation within actors and postpone water shortage situations. Furthermore, numerical tools can help to corroborate decisions or to provide evidence of risks that may not have been foreseen, contributing to scientific arguments to address potential conflicts among stakeholders. As such, the implementation of a reservoir inflow forecasting and risk visualization tool may provide more flexibility to water management at the level of the Arzal dam.

Open Access This chapter is distributed under the terms of the Creative Commons Attribution-NonCommercial 2.5 License (http://creativecommons.org/licenses/by-nc/2.5/), which permits any noncommercial use, duplication, adaptation, distribution, and reproduction in any medium or format, as long as you give appropriate credit to the original author(s) and the source, a link is provided to the Creative Commons license, and any changes made are indicated.

The images or other third party material in this chapter are included in the work's Creative Commons license, unless indicated otherwise in the credit line; if such material is not included in the work's Creative Commons license and the respective action is not permitted by statutory regulation, users will need to obtain permission from the license holder to duplicate, adapt, or reproduce the material.

\section{References}

Bressers H, de Boer C, Lordkipanidze M, Özerol G, Vinke-De Kruijf J, Furusho C, La Jeunesse I, Larrue C, Ramos MH, Kampa E, Stein U, Tröltzsch J, Vidaurre R, Browne A (2013a) Water governance assessment tool with an elaboration for drought resilience. DROP project, University of Twente, Enschede

Bressers H, de Boer C, Lordkipanidze M, Özerol G, Vinke-de Kruijf J, Farusho C, La Jeunesse I, Larrue C, Ramos M-H, Kampa E, Stein U, Tröltzsch J, Vidaurre R, Brown A (2013b) Water governance assessment tool. http://doc.utwente.n1/86879/1/Governance-Assessment-ToolDROP-final-for-online.pdf. Accessed 14 Dec 2015

Bressers H, de Boer C, Lordkipanidze M, Özerol G, Vinke-De Kruijf J, Furusho C, La Jeunesse I, Larrue C, Ramos M-H, Kampa E, Stein U, Tröltzsch J, Vidaurre R, Browne A (2013c) Water Governance Assessment Tool. With an Elaboration for Drought Resilience. Report to the DROP project, CSTM University of Twente, Enschede

Brochet P (1977) La sécheresse de 1976 en France. Aspects climatologiques et consequences. Hydrol Sci Bull XXII 3(9):393-411

Corti T, Muccione V, Köllner-Heck P, Bresch D, Seneviratne SI (2009) Simulating past droughts and associated building damages in France. Hydrol Earth Syst Sci 13:1739-1747

European Drought Centre EDC (2013) European Drought Impact Report Inventory (EDII) and European Drought Reference (EDR). http://www.geo.uio.no/edc/droughtdb/. Accessed 22 Oct 2015 
Le Roy Ladurie E, Rousseau D, Vasak A (2011) Les fluctuations du climat de l'an mil à aujourd'hui. Fayard, Paris, p 321

Mérillon Y, Chaperon P (1990) La sécheresse de 1989. La Houille Blanche N`5 (Août 1990), 325340. doi: $10.1051 / \mathrm{hb} / 1990025$

Pirard P, Vandentorren S, Pascal M, Laaidi K, Le Tertre A, Cassadou S, Ledrans M (2005) Summary of the mortality impact assessment of the 2003 heat wave in France. Eurosurveillance Monthly Release 10(7):554. http://www.eurosurveillance.org/ViewArticle. aspx?ArticleId=554. Accessed 20 Oct 2015

Plan National d'Adaptation au Changement Climatique 2011-2015 (2011) ONERC, p 73

Poumadère M, Mays C, Le Mer S, Blong R (2005) The 2003 heat wave in France: dangerous climate change here and now. Risk Anal 25(6):1483-1494

Richard E (2013) L'action publique territoriale à l'épreuve de l'adaptation aux changements climatiques. Thèse de doctorat Université de Tours, p 520. http://www.theses.fr/ 2013TOUR1802/document. Accessed 16 Dec 2015

Robine JM, Cheung SL, Le Roy S, Van Oyen H, Herrmann FR (2007) Report on excess mortality in Europe during summer 2003. EU community action programme for public health, p 15

UNEP (2004) Impacts of summer 2003 heat wave in Europe. Environ Alert Bull (no2, United Nations Environment Programme Nairobi)

Vidal J-P, Soubeyroux J-M (2008) Impact du changement climatique en France sur la sécheresse et l'eau du sol. In: Magnan J-P, Cojean R, Cui YJ, Mestat P (eds) SEC 2008-International symposium drought and constructions, vol 1, Laboratoire Central des Ponts et Chaussées, Marne-la-Vallée, France, pp 25-31

Vidal J-P, Martin E, Franchisteguy L, Habets F, Soubeyroux J-M, Blanchard M, Baillon M (2010) Multilevel and multiscale drought reanalysis over France with the Safran-Isba-Modcou hydrometeorological suite. Hydrol Earth Syst Sci 14:459-478

Zaidman MD, Rees HG, Young AR (2002) Spatio-temporal development of streamflow droughts in north-west Europe. Hydrol Earth Syst Sci 5:733-751 